\title{
Role of Employee Engagement Frame Work In Private Sector Insurance Companies
}

\author{
Binu B Pillai ${ }^{1}$, Dr. Balu L ${ }^{2}$, Dr. Ramesh Unnikrishnan ${ }^{3}$ \\ ${ }^{1}$ Research Scholar, Presidency University, Bengaluru, Karnataka, India \\ Assistant Professor, ICCS College of Engineering \& Management, Thrissur, Kerala, India \\ E Mail: bbpfatem@gmail.com, binu.bpillai@presidencyuniversity.in \\ ${ }^{2}$ Research Supervisor, HOD, School of Commerce, \\ Presidency University, Bengaluru, Karnataka, India \\ E Mail: balul@presidencyuniversity.in \\ ${ }^{3}$ Director AICTE, E Mail: rameshumnr@gmail.com
}

\begin{abstract}
The current examination study was limited to just private area insurance agencies arranged in Pathanamthitta District, Kerala, India. The investigation was exact; in this way, the quantitative examination was utilized for information social occasion and examination. The investigation was led through the review strategy. To do the examination, the organized survey procedure was utilized to increase knowledge into the issues investigated in the examination. For the investigation, both essential and auxiliary information was gathered, to accomplish the figured destinations. The essential information was gathered from employees working in all frameworks. The optional information was gathered from diaries, books and sites. This investigation depends on information gathered from five Private insurance agencies in Pathanamthitta locale. The rise of the Private area insurance agency has achieved huge changes in the occupation market. The dependability of the survey was tried with the Cronbach's Alpha technique utilizing factual programming. All the Descriptive examination and measurable inferential investigation were finished utilizing SPSS and P-esteem subtleties just displayed for translations. Karl Pearson's relationship coefficient is utilized to examine and decipher the information. The aftereffects of the examination demonstrate that employees are not exceptionally connected with on account of perspectives, for example, uneasiness with respect to the association culture, deficient assets uphold, resistance of-employees uphold, disappointment in the activities and conduct of the senior administration, disturbance concerning organization Human Resources strategies and techniques and upsetting chances. It is assumed that the aftereffects of the current investigation will be of significance to associations, which try to upgrade the degrees of engagement of employees' status. Further, the consequences of the examination would illuminate the segments of employee engagement and hierarchical adequacy. The result of the examination would likewise help associations a lot in detailing reasonable projects and suitable strategies to improve authoritative adequacy.
\end{abstract}

Key words:

Private Insurance Companies, Employee Engagement, Organizations, Performance

\section{Introduction}

Managing human resources has become very important for all organizations in today's scenario. Organizations are competing in the global market. They are experiencing difficulties and challenges in managing human resources. To survive in the competitive world, organizations need to focus on the strength of their employees to achieve competitive advantage. It has become a big challenge in finding the right candidate, training, and preparing them. The asset which improves creativity and organizational innovation is a knowledgeable and skilled employee. HR professionals are working to develop innovative HR practices for engaging employees, motivating, and retaining them. As a result of these practices, the organizational performance and productivity are increased. In this fast and globalization era, helping employees to be engaged and productive is necessary for the organization to achieve their objectives. The roles of human resource organizations are changing and these changes influence their working style and performance. Culture lends support to this initiative. Organizational culture is comprised of characteristics perceived by the employees, which serve as a major force in influencing their 
behaviour. Employees should be compatible with organizational culture and perform their duties. Professionals ensure that the employees remain motivated to meet the organizational objectives and maximize effectiveness. Therefore, HR professionals need to improve employee engagement by treating the employee at workplace carefully. The present study focuses on employee engagement strategies adopted in Private sector Insurance companies in Pathanamthitta District.

Employee engagement is the methods or methodology, by which an association tries to assemble an organization between the association and its employees, with the end goal that: Employees completely comprehend and are resolved to accomplish the association's targets, and the association regards the individual yearnings and aspirations of its employees. We can likewise take a gander at employee engagement as the degree of responsibility and association an employee has towards his interrelation and its merit. In engagement, individuals utilize and communicate genuinely, intellectually and sincerely during their job execution. Employees who are locked into their work and to their associations give associations' significant upper hand, including higher profitability and lower employee turnover.

\section{Need for the Study}

This study is focused on employees of Private sector insurance companies, since the attrition rate in these industries is increasing alarmingly. To overcome the high rate of attrition level in insurance industry, the researcher intended to reveal the relationship and impact level of employee engagement level on intention to quit among the employees. This study helps to discover organizational drivers which can be channelized to enhance engagement levels of employees. Accordingly, the current investigation is attempted to gauge the employee engagement methodologies and its effect on hierarchical viability.First, different practices and exercises which are coordinated towards Employee Engagement are recognized.
Second, it would likewise help in understanding the drivers of Employee Engagement that these practices are focusing at. It would not just deliver the noticeable drivers of Employee Engagement yet additionally their general effect across different boundaries of Engagement and level of Engagement of various classes of private sector insurance company's employees. Third, this would empower the private area organizations to smooth out their endeavors and assets as Employee Engagement Practices by significance laid on various boundaries by various programming organizations and furthermore by a particular classification of employees that they are focusing any point of time.

\section{Statement of the Problem}

It is known fact that employee engagements are behaviorism of employee and his manners towards the work place environment. Employees who are engaged at greater levels have less intention to quit from the organization. Now a day private insurance sectors are facing major problem in the context of retaining talented employees, because of the constant opportunities to move further in their profession. The Private sector insurance companies meet a massive damage when its skilled employees quit immediately and go for better opportunities, and the organization has to spend unnecessarily towards recruiting new candidates. When the employees are wholly engaged in their job the company could be able to attain the importance of employee engagement.

Employee Engagement is sloping downward and there is a poignant disengagement among employees in the Private insurance company because of lack of good organizational environment and policies such as deficiency in management support, recognition and advancement, insufficient resources support etc. Though Insurance companies spend more interest in increasing the employee commitment and engagement, but the level of improvement in this area is proved to be less. 


\section{Objectives of the Study}

The objectives of the study are:

To measure the level of employee engagement at the Private sector Insurance companies in Pathanamthitta district.

$>$ To analyze the factors facilitating employee engagement in Private sector Insurance companies in Pathanamthitta district.

$>$ To study the association between factors affecting employee engagement and employee retention.

\section{Scope of the Study}

The scope of the study basically means all those things that will be covered in the research. The study covers steps measuring employee engagement which leads to employee retention and employee character influencing employee engagement. The study also aims at establishing good compensation system and suggests measures to improve employee engagement practices etc.

\section{Limitations of the Study}

The study is an empirical one based on perceptions of the employees. The study has been undertaken in Pathanamthitta district, though this area caters to diverse set of employees coming from all across Kerala, but generalization of the results may not be propagated. The study is limited to private insurance sector; therefore, generalization of all the sectors may not be made.

\section{Literature Review}

Csikzentiminalyi (1975)has explained that employee engagement is the level of duty and commitment an employee has towards their affiliation and its characteristics. The creator has moreover communicated that drew an employee thinks about the business setting, and work with partners to improve execution inside the occupation to support the affiliation. The Organization must endeavor to make and support engagement, which requires a two-course association among chief and employee. Taking everything into account, employee engagement is a boundary that decides the relationship of an individual with the association and engagement be all the more firmly connected with the current development of occupation contribution.

Kanungo (1982)has kept up that work inclusion is an intellectual or conviction condition of mental distinguishing proof. Occupation association is a plan to depend upon both need noticeable and the ability of something critical to satisfying these necessities. Thusly work consideration results from a scholarly judgment about the necessities satisfying limits of the work. Occupations in this view are joined to one's psychological self-representation. Engagement varies from an occupation as it is concerned more with how the individual employees carry on during the presentation of their work. Also, engagement includes the dynamic usage of sentiments. Finally, engagement may be considered as an archetype to work for relationship in that individuals who experience significant engagement in their positions should come to identify with their positions.

Harvard Business Review (2005)is an assortment of expositions on employee execution. This assortment analyzes the employee audit measure from numerous points, investigating why we detest it, how it very well may be better, and how evaluations ought to contrast contingent upon the employee. The abstract is intended to bring administrators and experts the major data they have to remain serious in a quick-moving world.

Kahn William (1990)did one of the most powerful inquires of engagement in his exploration work 'Mental states of individual engagement and disengagement at work.' Conceptually, Kahn started with the reasoning that, "individuals' connection and separation to their job shifts. Kahn usesthese terms to depict these adjustments are 'individual engagement' and 'individual disengagement', which allude to the "practices by which individuals acquire 
or leave out their own selves during work job exhibitions. These terms made by Kahn join past contemplations taken from motivation theories that people need self-verbalization and free work in their work lives as is ordinarily done.

Bakker (2008)has clarified that there are at any rate four reasons why labourers perform in a way that is better than non-drew in labourers. Drawn in employees frequently experience positive feelings, including satisfaction, delight and eagerness; experience better wellbeing; make their own work and individual assets, and move their engagement to other people. An objective coordinated conduct is encouraged when individuals are occupied with their work since they have the energy and the inspiration to embrace the activity. This causes them to accomplish better execution as well as increment their odds for a superior vocation improvement.

\section{Research Design}

Studies layout is a master plan specifying the strategies and processes guiding the researcher to accumulate their statistics and evaluation for his or her studies. The most commonplace studies design that the researchers always uses is exploratory, descriptive and causal. Descriptive studies are typically more formal and dependent than exploratory studies (malhotra, 2005).

\section{Area of Study}

The emergence of Private sector insurance companies in Kerala has brought about vast changes in the job market. Hitherto, there have been not many studies about Private sector insurance companies about Employee Engagement. Therefore, the researcher selected Pathanamthitta district for conducting a study on employee engagement strategies adopted in Private sector insurance companies.

\section{Sample Design}

A sample is taken from the population and afterwards, the survey is directed. A sample is a piece of the population which is concentrated to make surmising's about the entire population. In the event that the sample is satisfactory, it will have similar qualities of the population (Zikmund, 2003) and the discoveries are typically used to make decisions about the population. Along these lines, a decent sample is a tiny adaptation of the population.

\section{Sample Unit}

The purpose of the study is to study employee engagement strategies followed in Private sector insurance companies. Moreover, study focuses on private sector Insurance companies in Pathanamthitta district only and hence ING Vysys, Reliance, HDFC Standard Life, Max Life Insurance Co. Ltd. and ICICI Prudential Life Insurance Co. Ltd. were taken as a sample unit. So employees of these companies serve as respondent.

\section{Sample Technique}

In the present study, Simple Random Sampling was used for the selection of respondents from Private sector Insurance companies.

\section{Sample Size}

Sample size influences how the sample discoveries precisely speak to the population (Burns and Bush, 2010). The bigger the sample is, the almost certain that the speculations are an exact impression of the population (Saunders, Lewis and Thornhill, 2009). Tabachnick and Fidell (2007) set up that a sample size of 300 is satisfactory for factor examination and for relapse investigation a sample size of $\mathrm{N} \geq$ $50+8 \times M$ is sufficient where $M$ is the number of independent variables.

\section{Data Collection}

In this research study, both the primary data and secondary data are applied. The primary data are collected through the survey, and the secondary data 
are collected from websites, books, journals and magazines.

\section{Statistical Tools}

Cronbach's alpha coefficient Correlation

\section{Data Interpretation and Findings}

Reliability Analysis: Reliability is concerned about the capacity of an instrument to quantify reliably for example it alludes to the degree to which a scale produces reliable outcomes if the estimations are rehashed various occasions. It should be noticed that the reliability of an instrument is firmly connected with its legitimacy. An instrument can't be substantial except if it is dependable. In any case, the reliability of an instrument doesn't rely upon its legitimacy. The analysis on reliability is called reliability analysis. Internal consistency is usually measured with Cronbach's alpha, a statistic calculated from the pair wise correlations between items. Cronbach's alpha reliability coefficient normally ranges between 0 and 1 . However, there is actually no lower limit to the coefficient. The closer Cronbach's alpha coefficient is to 1.0 the greater the internal consistency of the items in the scale.

\begin{tabular}{|l|c|}
\hline \multicolumn{1}{|c|}{ Dimension } & Cronbach's Alpha \\
\hline Working Place & 0.877 \\
\hline Health And Safety Measure & 0.906 \\
\hline Family Welfare Measures & 0.828 \\
\hline Rewards And Recognition & 0.86 \\
\hline Pay And Benefits & 0.877 \\
\hline Leadership And Management & 0.94 \\
\hline Communication At Work & 0.841 \\
\hline Opportunities For Growth & 0.802 \\
\hline Employment Experience & 0.946 \\
\hline Work/Life Balance; Stress & 0.912 \\
\hline Training Programs & 0.767 \\
\hline Employee engagement & 0.852 \\
\hline
\end{tabular}

companies.

Interpretation:The overall Cronbach's alpha coefficient obtained for the questionnaire was 0.912 for the total 89 items. Owing to the total value being above 0.7 , the scale was deemed to be a reliable measure for examining the current sample. Reliability analysis for all factors were also done and values range from 0.946 (Employment Experience) to 0.767 (Training Programs). Since the value Cronbach's alpha coefficient of all factors are above 0.7 , all the factors have good internal consistency.

\section{Hypothesis: Factors facilitating employee} engagement in Private sector Insurance
Null Hypothesis (H0): There is no relationship between working place, Health and Safety Measures, Family Welfare Measures, Pay and Benefits, Leadership and Management, Communication at Work, Opportunities for Growth, Work/Life Balance and Training Programs and Employee engagement 


\begin{tabular}{|c|c|c|c|}
\hline Variable 1 & Variable 2 & Correlation Coefficient & $\mathrm{P}$-value \\
\hline \multirow{10}{*}{ Employee Engagement } & Working Place & $0.473 * *$ & .000 \\
\hline & Health And Safety Measure & $0.289 * *$ & .000 \\
\hline & Family Welfare Measures & $0.310 * *$ & .000 \\
\hline & Rewards And Recognition & $0.332 * *$ & .000 \\
\hline & Pay And Benefits & $0.448 * *$ & .000 \\
\hline & Leadership And Management & $0.418 * *$ & .000 \\
\hline & Communication At Work & $0.422 * *$ & .000 \\
\hline & Opportunities For Growth & 0.008 & 0.975 \\
\hline & Work/Life Balance; Stress & $0.552 * *$ & .000 \\
\hline & Training Programs & $0.414 * *$ & .000 \\
\hline
\end{tabular}

Interpretation: Since p-value <0.01 for all factors (except opportunities for growth), Null hypothesis is rejected at $1 \%$ level of significance.

Thus factors like working place, Health and Safety Measures, Family Welfare Measures, Pay and Benefits, Leadership and Management, Communication at Work, Work/Life Balance and Training Programs have a bearing on Employee Engagement. Opportunities for growth have no significant influence on employee engagement.

Among the factors, work-life balance has high correlation coefficient (0.552), which means they move in same direction $55.2 \%$ of times. So by providing better work-life balance, the company can significantly improve the employee engagement.

Following work-life balance, Working place $(\mathrm{r}=0.473)$ Pay and benefits $(\mathrm{r}=0.448)$, Communication at work $(\mathrm{r}=0.422)$, leadership and management $(\mathrm{r}=0.418)$ and training programs also have moderate relationship with employee engagement.

Rewards and Recognition ( $\mathrm{r}=0.332$ ), Family Welfare Measures $(r=0.310)$ and Health and Safety Measures ( $r=0.289)$ have low relationship with employee engagement. The company can look for improving these factors especially Rewards and Recognition that will improve the employee morale which in turn may improve employee engagement.

It can also be inferred that Opportunities for Growth factor do not have significant correlation with employee engagement. The company can look for improving career development programs provided. To identify exact impact of these factors on employee engagement, regression analysis was done.

\section{Hypothesis: Factors influencing employee engagement have a bearing on Employee retention.}

Null Hypothesis (H0): There is no relationship between factors influencing employee engagement and Employee retention

Alternate Hypothesis (H1): There is relationship between factors influencing employee engagement and Employee retention 


\begin{tabular}{|c|c|c|c|}
\hline Variable 1 & variable 2 & Correlation coefficent & P-value \\
\hline \multirow{10}{*}{ Employee Retention } & Working Place & $0.375^{* *}$ & .000 \\
\hline & Health And Safety Measure & $0.244 * *$ & .000 \\
\hline & Family Welfare Measures & $0.263 * *$ & .000 \\
\hline & Rewards And Recognition & $0.218^{* *}$ & .000 \\
\hline & Pay And Benefits & $0.559 * *$ & .000 \\
\hline & Leadership And Management & $0.201 * *$ & .000 \\
\hline & Communication At Work & $0.286^{* *}$ & .000 \\
\hline & Opportunities For Growth & 0.094 & 0.975 \\
\hline & Work/Life Balance; Stress & $0.435^{* *}$ & .000 \\
\hline & Training Programs & $0.533 * *$ & .000 \\
\hline
\end{tabular}

** $\square$ Correlation is significant at 0.01 levels

Interpretation: Since p-value $<0.01$ for all factors (except opportunities for growth), Null hypothesis is rejected at $1 \%$ level of significance.

Thus factors like working place, Health and Safety Measures, Family Welfare Measures, Pay and Benefits, Leadership and Management, Communication at Work, Work/Life Balance and Training Programs have a bearing on Employee retention. Opportunities for growth have no significant influence on Employee retention. Of the factors, Pay, and benefits have a high correlation with employment experience $(\mathrm{r}=0.559)$ followed by Training programs $(\mathrm{r}=0.533)$.

\section{Recommendations}

The organization has to build a system where the issues of the employees are addressed at the earliest, and the grievances are redressed speedily. Moreover, a feedback mechanism has to be built where the problems faced by the employees during the assignment can be recorded and in future, other employees will not suffer.

$>$ The researcher suggests the companies provide better parking facilities to all the employees. o The company can look for providing yoga and meditation facilities to their employees who help them to reduce stress and help in self-management.

$>$ The company can provide food at subsidized rates to all employees.

$>$ The company by providing an educational loan to the employees and employee's children motivates them to pursue higher studies/ certification exams related to their work and also help them to excel in the work.

$>$ The company can plan on providing additional recreation facilities which help employees to take off from their routine life and help in boosting their morale.

$>$ Employees should be rewarded and recognized for the fair work done.

$>$ Working overtime being common in Private sector insurance industry, the company can look for providing overtime salary but with stringent regulations, as providing over time salary should not mislead hard working employees to spend additional unwanted 
time at the office and there by affecting their work-life balance too.

\section{Conclusions}

The study gives us knowledge into the engagement methodologies embraced in Private area insurance agencies in Pathanamthitta locale. The investigation shows that employees are not exceptionally connected within the light of angles, for example, uneasiness with respect to the association culture, deficient assets uphold, absence of co-employees uphold, disappointment in the activities and conduct of the senior administration, irritation concerning organization Human Resources strategies and techniques and troubling chances. During the investigation, the analyst has discovered that practically all Private area insurance organizations are very enthusiastic about the idea and the act of 'Connecting with' their employees.Likewise, it additionally illuminates the drivers that assume a more significant part in 'Drawing in' different degrees of Private area insurance organizations' employee is viz. Junior Level, Middle Level and Senior Level.Eventually, the prizes that can be normal out of such smoothed out and centered 'Engagement' endeavors are many. A connected with labor force is glad and a dedicated labor force. It unquestionably gives an additional edge to the association helping it stay serious.

\section{References}

[1] Bakker, A. B. and Demerouti, E. "Towards a model of work engagement", Career Development International, Vol. 13, pp. 209-223, 2008.

[2] Csikszentimihalyi, M. "Flow: The psychology of optimal experience", New York: Harper. 1990. Deci, E.L. and Ryan, R.M. "The support of autonomy and the control of behaviour", Journal of and Social psychology, Vol. 53, pp. 1024-1037, 1987.

[3] Kahn, W. A. "Psychological conditions of personal engagement and disengagement at Work", Academy of Management Journal,
Vol. 33(4), pp. 692- 724,[Online]Url: http://www.jstor.org/stable/pdfplus/256287. pdf?acceptTC $=$ true (Retrieved on 23rd December 2011), 1990.

[4] Kahn, W.A. "To Be Fully There: Psychological Presence at Work", Human Relations, Vol. 45, pp.321-50, 1992. 68. Kanugo, R.N. "Work Alienation: An Approach", Praeger Publishers: New York, pp. 82-97, 1982.

[5] Kanungo, R.N. "Measurement of Job and Work Involvement", Journal of Applied Psychology, Vol. 67, pp. 341-349, 1982. 